\title{
Antimicrobial Activity of a Formulation of Libidibia ferrea L. against Microorganisms of the Dental Biofilm
}

\author{
Raquel de Oliveira Marreiroㅁ, Maria Fulgência Costa Lima Bandeira1 ${ }^{1}$, Carina Toda1, \\ Fábio Correia Sampaio², Tatiane Pereira de Souza ${ }^{3}$, Gisely Naura Venâncio4, \\ Wanderleia Monteiro de Souza ${ }^{1}$, Nikeila Chacon de Oliveira Conde ${ }^{1^{*}}$ (]) \\ ${ }^{1}$ School of Dentistry, Federal University of Amazonas, Manaus, AM, Brazil \\ ${ }^{2}$ Federal University of Paraíba, Health Sciences Center, Department of Clinical and Social Dentistry, João Pessoa, PB, Brazil \\ ${ }^{3}$ Faculty of Pharmaceutical Sciences, Federal University of Amazonas, Manaus, AM, Brazil \\ ${ }^{4}$ Manaus Municipal Health Department, SEMSA, Manaus, AM, Brazil \\ Email: *nikeilaconde@ufam.edu.br
}

How to cite this paper: de Oliveira Marreiro, R., Bandeira, M.F.C.L., Toda, C., Sampaio, F.C., de Souza, T.P., Venâncio, G.N., de Souza, W.M., de Oliveira Conde, N.C. (2020) Antimicrobial Activity of a Formulation of Libidibia ferrea L. against Microorganisms of the Dental Biofilm. Advances in Microbiology, 10, 434-442. https://doi.org/10.4236/aim.2020.109032

Received: August 14, 2020

Accepted: September 13, 2020

Published: September 16, 2020

Copyright $\odot 2020$ by author(s) and Scientific Research Publishing Inc. This work is licensed under the Creative Commons Attribution International License (CC BY 4.0).

http://creativecommons.org/licenses/by/4.0/

(c) (i) Open Access

\begin{abstract}
This study aimed to evaluate the antimicrobial activity of the extract of Libidibia ferrea L. (228.022-INPA) and a mouthwash formulation against microorganisms of the dental biofilm. The extract of Libidibia ferrea L. was prepared and formulated with an alcohol-free mouthwash. The Minimum Inhibitory Concentration-MIC was determined by microdilution and cell viability was evaluated through fluorescence. The MICs for the extract were 4.375 $\mu \mathrm{g} / \mathrm{mL}$ (Streptococcus mutans), $3.750 \mu \mathrm{g} / \mathrm{mL}$ (Streptococcus oralis), 4.375 $\mu \mathrm{g} / \mathrm{mL}$ (Lactobacillus casei). In contrast, for the mouthwash, the MICs were $6.000 \mu \mathrm{g} / \mathrm{mL}$ (bacteriostatic against Streptococcus mutans and bactericidal against Streptococcus oralis). In $1.250 \mu \mathrm{g} / \mathrm{mL}$ of the extract, the number of viable cells measured by fluorescence tests was $16.47 \%$ and $14.12 \%$ for Streptococcus mutans and Lactobacillus casei, respectively. For the mouthwash $(1.000 \mu \mathrm{g} / \mathrm{mL}), 20.60 \%$ of viable cells for Streptococcus mutans, and $9.60 \%$ for Lactobacillus casei were observed. It can be concluded that the extract and its mouthwash containig Libidibia ferrea L. showed antibacterial activity against microorganisms from the dental biofilm.
\end{abstract}

\section{Keywords}

Mouthwash, Juca, Natural Products

\section{Introduction}

Dental biofilm is formed in an orderly manner, possessing a diversified and 
complex microbial composition that, over time, remains relatively stable, known as microbial homeostasis. The tangle of various synergistic and antagonistic interactions leads to microbial interdependencies providing resilience to the biofilm so that changes in competitiveness among oral microorganisms can lead to the dysbiosis occurrence, and this has a vital role in the development of diseases such as caries and periodontal disease [1].

The variety of natural products is an important source in the search for bioactive compounds. Plants have a wide range of secondary metabolites relevant to drug discovery for various diseases and infections by microorganisms [2].

In Brazil, medicinal plants are evidenced as an incalculable cultural heritage and represent an essential resource for the health of the population. The Amazon stands out for having high biodiversity, popular and traditional knowledge of medicinal plants, making natural products the basis for disease prevention and treatment [3] [4] [5].

Several types of research using Amazonian flora plants have been carried out to prove their efficacy as an antibacterial agent on microorganisms of dental biofilm [6] [7] [8].

Libidibia ferrea is a plant species widely used in folk medicine, popularly known as "Juca" or "ironwood". Currently, the scientific name for this species is Libidibia ferrea (Mart. Ex Tul.) L.P. Queiroz var. ferrea, whose basionym is Caesalpinia ferrea Mart. ex Tul. (Caesalpiniaceae). It is a species of the Leguminosae family, one of the largest among the dicotyledons, found in Brazil's tropical regions, especially in the North and Northeast [9]. To verify the chemical compounds of the hydroalcoholic extract of $L$. ferrea, studies on the phytochemical profile indicated the presence of flavonoids, saponins, steroids, tannins, and coumarins that have a high antioxidant and enzymatic potential [10].

In addition, through chromatographic and spectrophotometric analysis of phenolic compounds from fruits of Libidibia ferrea Martius it was observed that its main constituents are hydrolyzable tannins (gallic acid and ellagic acid). Performing the qualitative analysis, the separation and identification of these markers was verified and the quantitative analysis of the phenolic compounds allowed their quantification by ultraviolet/visible [11].

The present study evaluated the antimicrobial activity of the extract and a mouthwash formulation from Libidibia ferrea $L$. extract on microorganisms in the oral cavity.

\section{Materials and Methods}

\section{Mouthwash formulation}

The botanical species Libidibia ferrea L. (228,022-INPA) was collected at the National Research Institute of the Amazon (INPA) and processed at the Faculty of Pharmaceutical Sciences (FCF/UFAM). The juca extractive solution was prepared with 7.5 grams of the juca pod in $500 \mathrm{~mL}$ of distilled water and $500 \mathrm{~mL}$ of alcohol at $96^{\circ} \mathrm{C}$ in decoction for 15 minutes in a thermal blanket and under reflux. After this period, the material was removed, cooled, filtered, and taken to 
Spray Dry.

The preparation of the Libidibia ferrea L. mouthwash followed the methodology proposed by [12], being defined as the concentration of $1 \%$ of the extract of Libidibia ferrea $\mathrm{L}$. in the mouthwash solution. The other components were: sodium benzoate $(0.06 \mathrm{~g})$, saccharin $(0.03 \mathrm{~g})$, glycerin $(0.8 \mathrm{ml}), 80 \%$ tween $(0.08$ $\mathrm{ml}), 20 \%$ tween $(0.08 \mathrm{ml})$, oil of mint $(0.08 \mathrm{~mL})$ and distilled water $(20 \mathrm{~mL})$.

Evaluation of the minimum inhibitory concentration (MIC) of the extract and mouthwash of Libidibia ferrea $\mathrm{L}$.

The microorganisms used were: Streptococcus mutans (ATCC25175), Streptococcus oralis (ATCC10557), Streptococcus salivarius (ATCC7073) and Lactobacillus casei (ATCC7469), provided by the laboratory of the National Institute for Health Quality Control of the Oswaldo Cruz Foundation (Rio de Janeiro).

The microorganisms were reactivated in BHI (Brain Heart Infusion-DIFCO) nutrient agar broth, in $10 \times 150 \mathrm{~mm}$ test tubes, incubated at $37^{\circ} \mathrm{C}$ for 24 hours in aerophilic, for S. oralis, S. salivarius, and L. casei, and in microaerophilia for $S$. mutans. The entire procedure was performed in a laminar flow hood. Aliquots of the bacteria were removed with a sterile platinum loop of $5 \mathrm{~mm}$ in diameter and inoculated in $5 \mathrm{~mL}$ of sterile BHI broth in $10 \times 150 \mathrm{~mm}$ test tubes. The suspensions were vortexed until they became homogeneous. The inoculum was standardized using the McFarland \# 0.5 scale to provide a $10^{8} \mathrm{CFU} / \mathrm{mL}$ standard.

The antimicrobial activity of the Libidibia ferrea L. extract and mouthwash was determined according to the Minimum Inhibitory Concentration (MIC) methodology in microdilution proposed by [13] [14], adapted by [8]. The $0.12 \%$ chlorhexidine digluconate was used as a positive control.

96-hole microplates ("U" shaped) were used so that each well had a final volume of $100 \mu \mathrm{L}$. On the plaque, the columns were distributed in the numbers 1 to 12 and the lines in the letters " $\mathrm{A}$ " to " $\mathrm{H}$ ". The juca extract and rinse were distributed in the wells to contain the different concentrations of the test substances. The dilution system was controlled by the volume of the test products, occupying wells 2 to 11 . In the same wells, a standard volume of inoculum $(20 \mu \mathrm{L})$ was added, and the final volume was supplemented with the medium.

Column 01 represented the sterility of the test substance, rinse or extract + medium without bacteria. Column 12 represented the viability of the bacteria, medium + inoculum, without test product. Line G represented the vehicle (negative control) and line $\mathrm{H}$ the $0.12 \%$ chlorhexidine digluconate (positive control). A single microplate was used for each microorganism, and the jucá rinse was tested on lines A, B, and C and jucá extract on lines E, F, and G.

After filling all wells, the microplates were sealed with parafilm and incubated at $370 \mathrm{C}$ for 24 hours, in aerophilic for S. oralis, L. casei and S. salivarius, and in microaerophilia for $S$. mutans. After the incubation period, $30 \mu \mathrm{L}$ of resazurin reagent prepared in aqueous solution $(0.01 \%, 10 \mathrm{mg}$ diluted in $100 \mathrm{~mL})$ were included in the wells. The plates were again incubated for 30 minutes.

The absence of color change in the holes was interpreted as a microorganism sensitive to the tested solution. To verify the minimum inhibitory concentration 
activity (MIC), when possible, $100 \mu \mathrm{L}$ were removed from the wells referring to the mouthwash/juca extract in different concentrations (lines $\mathrm{C}$ and G, respectively), sown in Petri dishes with $\mathrm{BHI}$ agar and incubated at $37^{\circ} \mathrm{C}$ in aerophilia and microaerophilic, according to the microorganism tested, for 24 hours to confirm the presence of viable bacteria.

\section{Cell viability analysis by fluorescence technique}

The cell viability activity of the $0.6 \%$ extract and the $1 \%$ Libidibia ferrea $\mathrm{L}$. mouthwash were determined according to the fluorescence methodology proposed by [15] against $S$. mutans (UA 159-2-ATCC 700610) and L. casei (ATCC7469).

Solutions were prepared for the extract, and the mouthwash established as Mother Solution (extract /mouthwash + BHI medium in the proportion of 1:1).

The cell viability test required MIC to be performed as described in the previous topic. The MICs of the extract and mouthwash solutions were determined in different concentrations. From the result of the MICs of the extract and the jucá mouthwash, the observation of cell viability of these concentrations was re-evaluated by reading fluorescence through the LIVE/DEAD ${ }^{\circ}$ BacLight $^{\text {Ts }}$ Bacterial Viability Kit L13152 (Molecular Probes, Eugene, United States). In this system, viable cells without damage to the cell wall are stained green (Component A: SYTO 9), and red (Component B: propidium iodide) are the cells with damage to the cell membrane. Bacterial suspensions were prepared to construct the standard curve, through known concentrations of viable bacteria and dead cells. Two falcon ${ }^{\otimes}$ tubes containing $3 \mathrm{~mL}$ of BHI broth with the reactivated bacteria were centrifuged for 15 minutes, after which the supernatant was removed, and the precipitate was resuspended with $240 \mu \mathrm{L}$ of $\mathrm{NaCl}$ and homogenized in the Vortex ${ }^{\oplus}$. Then $4.8 \mathrm{~mL}$ of $\mathrm{NaCl}$ was added to the tube representing live bacteria, and in the other tube representing the dead cells, $4.8 \mathrm{~mL}$ of $70 \%$ isopropyl alcohol was added. The two tubes were incubated at room temperature for 60 minutes with shaking every 15 minutes. They were again centrifuged for another 15 minutes, and the supernatant removed and the precipitate resuspended with $2.4 \mathrm{~mL}$ of $\mathrm{NaCl}$.

Bacterial cell patterns were prepared by proportions of known concentrations of viable bacteria: dead cells with 0:100 (0 viable bacteria per 100 dead cells); 20:80; 50:50; 80:20 and 100:0, respectively. 96-well plates of black color for luminosity control (Greiner-Bio-One) were used to construct the standard curves. The proportions of concentration of live bacteria and dead cells were placed in wells $\mathrm{A} 1$ to $\mathrm{A} 5$. In wells $\mathrm{B} 1$ to $\mathrm{B} 5,100 \mu \mathrm{L}$ of the aliquots of the MIC result were placed, considering two concentrations ahead and two after. Equal volumes of SYTO9 and Propidium Iodide were mixed in a miniature vortex/mixer (Thomas Scientific, New Jersey, USA) that reaches a speed of $2.800 \mathrm{rpm}$ for 3 minutes. A volume of $30 \mu \mathrm{L}$ of the mixture was added to the fluorescence plate. The wells were then incubated in the dark and at room temperature for $15 \mathrm{~min}$. The reading was performed by fluorescence intensity through the multi-mode microplate reader (FLUORStar Optima, BMGLab Tech, Germany) under an excitation filter 
of $485 \mathrm{~nm}$ and emission with 520 and $620 \mathrm{~nm}$ to detect green and red respectively. The results obtained were tabulated and presented through a descriptive analysis [16].

\section{Results and Discussion}

The evaluation of the antibacterial activity of the Libidibia ferrea L. extract and mouthwash against strains of Streptococcus mutans, Streptococcus oralis, Streptococcus salivarius, and Lactobacillus casei, using the microdilution test in microplate showed that the extract of Libidibia ferrea L. to $0.6 \%$ showed bactericidal antibacterial activity against $S$. mutans, $S$. oralis and $L$. casei at concentrations of $4.375 \mu \mathrm{g} / \mathrm{mL} ; 3.750 \mu \mathrm{g} / \mathrm{ml} ; 4.375 \mu \mathrm{g} / \mathrm{mL}$, respectively. This result reinforces the study by [17] in which they proposed a formulation of a mouthwash using Juca extract, concluding that this product is viable. Considering the good results achieved in the study about the antimicrobial activity against $S$. mutans, and $S$. oralis. Regarding $S$. salivarius, there was no activity of extract and formulation.

The juca mouthwash showed bacteriostatic activity against $S$. mutans and bactericide for $S$. oralis at a concentration of $6.000 \mu \mathrm{g} / \mathrm{mL}$ for both. However, against $L$. casei, no inhibitory activity was observed. Sterility checks of the test product + medium were performed on the four plates used to assess MIC, in column 1 ; in column 12 , the viability of the inoculum + medium, with a more purple color, was verified; in line $\mathrm{D}$, the antibacterial activity of the $0.12 \%$ chlorhexidine mouthwash was evaluated, used as a positive control, where a blue color was observed, which indicates an antibacterial activity of the tested product. In line $\mathrm{H}$, the viability of the inoculum was verified, which obtained a pink color indicative of bacterial growth.

An adjuvant fluorescence test was performed for the juca extract and the mouthwash formulation against the $S$. mutans (UA 159/2) and L.casei (ATCC 7469) strains. The data indicated percentage values of viable cells at minimum inhibitory concentrations. The technique used allows good evaluation of viable cells and uses black opaque-walled 96-well plates. It must be pointed out that precision in fluorescence liquid samples charges its value: This technique does not allow the researcher to capture images. In this study, the MIC considered against $S$. mutans was $1.250 \mu \mathrm{g} / \mathrm{mL}$ for the extract and $1.000 \mu \mathrm{g} / \mathrm{mL}$ for the mouthwash, however, in the fluorescence assay, the presence of viable cells in these concentrations was found, corresponding to $16.47 \%$ and $20.60 \%$, respectively. For L.casei in the concentration considered minimal bactericidal by the reagent resazurin, it was $1.250 \mathrm{ug} / \mathrm{mL}$ for the extract and $1.000 \mathrm{ug} / \mathrm{mL}$ for the mouthwash, being possible to verify that there was a value of viable cells that corresponded to $14.12 \%$ and for the first and $9.6 \%$ for the second product. As a result, a low percentage of viable cells could be observed in the system under the target concentration of the extract and mouthwash formulation. These results were expected and must be interpreted as satisfactory since most mouthwashes 
are designed for controlling the levels of cariogenic bacteria and their plaque biofilms in the mouth.

It must be pointed out that the CBM did not coincide with the MICs, concerning the fluorescence results, which may be due to the performance of two methodologies with different readings, being the most accurate fluorescence technique, since the reading is performed with the use of a reader such as flow cytometer, spectrofluorometer, microplate reader and Optrode, a fiber-based spectroscopic system and not only visual [18]. It is a quick alternative to standard culture-based tests, using fluorescent dyes, which includes the evaluation of membrane potential and its integrity. It has advantages such as the quantification of cell death directly, in almost real-time, and not retrospectively from the knowledge of the colonies formed [18] [19] [20]. Besides, this seems to be the best proven and appropriate method for biofilm research [21].

The MIC test used was based on a colorimetric methodology and, therefore, the turbidity in which the method is compared to the standards generally of the Macfarland 0.5 scale is not able to give a standardized number of CFU for all strains. Therefore, reading is subjective. It also makes it difficult to compare different bacterial species as they have different optical densities [22]. Studies carried out to compare different techniques associated with inoculum standardization have shown that this standardization has a good correlation in the CFU count. However, it is not configured as a precision technique, as its reliability depends on subjective factors, such as training the observer, for example, adding uncertainties to the method [23].

In light of the above limitations, more robust techniques are necessary. According to the study by [21], the assessment of colony-forming units is not insufficient by convencional colorimetric techniques. On the contrary, the calculation of galvanizing efficiency is necessary. The fluorescence technique used in this work is regarded as suitable for more accurate and reproducible results because it is based on a calibration curve measured by stains that differ both in their spectral characteristics and their ability to penetrate healthy bacterial cells. Apart from the possible limitations of fluorescence techniques (e. g. not suitable for natural multispecies biofilm), this is not a problem for individual cell type evaluation like the tests carried out in this research. Hence, this study's results demonstrated the antibacterial efficacy of the juca extract and its mouthwash formulation against three of the four microorganisms tested.

In the microdilution test and reading by an oxy-reduction reaction, a first MIC test did not verify the extract/rinse activity against $L$. casei. However, when the fluorescence test was performed to verify cell viability, the result showed activity for this bacterium.

The non-activity verified against $S$. salivarius seems to be a satisfactory result considering that this microorganism represents one of the first ones in the initial colonization in the mucosa and the formation of biofilm [24]. Still, both the extract and the mouthwash was effective against $L$. casei, $S$. oralis, and $S$. mutans, 
the latter being considered the main bacterial species involved in the formation of the biofilm. Together, $S$. mutans and Lactobacillus, are particularly useful in the process of transforming sugar into acid thanks to the ability to be acidophilic bacteria [25] [26].

According to [27], the control of the growth of Streptococcus mutans causes a significant reduction in the formation of biofilm in the teeth. Its control can be adequately done by chemical and mechanical means. [28], emphasize the importance of therapeutic indications as a low cost and alternative method for the control of biofilm, which opens the way for research with products derived from medicinal plants.

Numerous studies such as [5] [17] [29] and [30], have already evaluated the antimicrobial activity of plant extracts from the Amazon in order to bring alternatives of chemical agents of natural origin for the control of dental biofilm and thus favor the maintenance of oral health.

Based on the results of the methodology used, it was possible to conclude that the Libidibia ferrea L. mouthwash showed antibacterial activity against the biofilm microorganisms tested.

\section{Funding Source}

Public Notice CT Amazônia FxB-Public Notice No. 55/2008-Track B, Process No. 575676/2008-6, coordinated by Researcher Nikeila Chacon de Oliveira Conde.

Participation of the Financing Source: research financing with equipment and supplies.

\section{Conflicts of Interest}

The authors declare no conflicts of interest regarding the publication of this paper.

\section{References}

[1] Marsh, P.D. and Zaura, E. (2017) Dental Biofilm: Ecological Interactions in Health and Disease. Journal of Clinical Periodontology, 44, 12-22. https://doi.org/10.1111/jcpe.12679

[2] Moro, I.S., Gondo, G.D.G.A., Pierri, E.G., Pietro, R.C.L.R., Soares, C.P., Sousa, D.P., et al. (2017) Evaluation of Antimicrobial, Cytotoxic and Chemopreventive Activities of Carvone and Its Derivatives. Brazilian Journal of Pharmaceutical Sciences, 53, 1-8. https://doi.org/10.1590/s2175-97902017000400076

[3] Barreto, B.B. and Vieira, R.C.P.A. (2015) Perception of Health Professionals about the Inclusion of Phytotherapy in Primary Health Care. Revista de Atenção Primária à Saúde, 18, 191-198.

[4] Santos, R.L., Guimaraes, G.P., Nobre, M.S.C. and Portela, A.S. (2011) Analysis of Phytotherapy as an Integrative Practice in the Unified Health System. Revista Brasileira de Plantas Medicinais, 13, 486-491. https://doi.org/10.1590/S1516-05722011000400014

[5] Oliveira, G.P., Souza, T.P., Caetano, S.K., Farias, K.S., Venancio, G.N., Bandeira, 
M.F.C.L., et al. (2013) Antimicrobial Activity in Vitro of Extracts of the Stem Bark and Fruit of Libidibia ferrea L. against Microorganisms of the Oral Cavity. Revista Fitos, 8, 73-160. https://doi.org/10.5935/1808-9569.20130004

[6] Simões, C.A.C.G., Conde, N.C.O., Venâncio, G.N., Milério, P.S.L.L., Bandeira, M.F.C.L. and Veiga Júnior, V.F. (2016) Antibacterial Activity of Copaiba Oil Gel on Dental Biofilm. Open Dentistry Journal, 10, 188-195.

https://doi.org/10.2174/1874210601610010188

[7] Vasconcelos, K.R.F., Veiga Junior, V.F., Rocha, W.C. and Bandeira, M.F.C.L. (2008) In Vitro Assessment of the Antibacterial Activity of a Dental Cement Constituted of a Copaifera multijuga Hayne Oil-Resin. Revista Brasileira de Farmacognosia, 18, 733-738. https://doi.org/10.1590/S0102-695X2008000500017

[8] Sampaio, F.C., Pereira, M.S., Dias, C.S., Costa, V.C., Conde, N.C. and Buzalaf, M.A. (2009) In Vitro Antimicrobial Activity of Caesalpinia ferrea Martius Fruits against Oral Pathogens. Journal of Ethnopharmacology, 124, 289-294.

https://doi.org/10.1016/j.jep.2009.04.034

[9] Freitas, A.C.C., Ximenes, N.C.A., Aguiar, J.S., Nascimento, S.C., Lins, T.U.L., Magalhães, L.R. et al. (2012) Biological Activies of Libidibia (Caesalpinia) ferrea var. parvifolia (Mart. ex Tul.) L.P. Queiroz Pod Preparations. Evidence-Based Complementary and Alternative Medicine, 2012, Article ID: 514134. https://doi.org/10.1155/2012/514134

[10] Pedrosa, T.N., Barros, A.O., Nogueira, J.R., Fruet, A.C., Rodrigues, I.C., Calcagno, D.Q., et al. (2016) Anti-Wrinkle and Anti-Whitening Effects of jucá (Libidibia ferrea Mart.) Extracts. Archives of Dermatological Research, 308, 643-654. https://doi.org/10.1007/s00403-016-1685-0

[11] Ferreira, M.R.A., Fernandes, M.T.M., Silva, W.A.V., Bezerra, I.C.F., de Souza, T.P., Pimentel, M.F., et al. (2016) Chromatographic and Spectrophotometric Analysis of Phenolic Compounds from Fruits of Libidibia ferrea Martius. Pharmacognosy Magazine, 12, 285-291. https://doi.org/10.4103/0973-1296.182165

[12] Zanin, S.M.W., Miguel, M.D., Barreira, S.M.W., Nakashima, T., Cury, C.D. and Costa, C.C. (2007) Mouthwasher: Active Principles and Development of a Formula with Hydroalcoholic Extract of Salvia officinalis L. Visão Acadêmica, 8, 19-24. https://doi.org/10.5380/acd.v8i1.11661

[13] NCCLS (2003) Performance Standards for Antimicrobial Disk Susceptibility Tests; Approved Standard-Eighth Edition. NCCLS Document M2-A8, NCCLS, Wayne, Pennsylvania.

[14] Andrews, J.M. (2007) Determination of Minimum Inhibitory Concentrations. Journal of Antimicrobial Chemotherapy, 41, 5-16. https://doi.org/10.1093/jac/48.suppl 1.5

[15] Filoche, S.K., Coleman, M.J. and Sissons, C.H. (2007) A Fluorescence Assay to Determine the Viable Biomass of Microcosm Dental Plaque Biofilms. Journal of Microbiological Methods, 69, 489-496. https://doi.org/10.1016/j.mimet.2007.02.015

[16] Vieira, S. (2004) Biostatistics, Advanced Topics. 2nd Edition, Elsevier, Rio de Janeiro.

[17] Marreiro, R.O., Bandeira, M.F.C.L., Souza, T.P., Almeida, M.C., Bendaham, K., Venâncio, G.N., et al. (2014) Evaluation of the Stability and Antimicrobial Activity of an Ethanolic Extract of Libidibia ferrea. Clinical, Cosmetic and Investigational Dentistry, 6, 9-13. https://doi.org/10.2147/CCIDE.S54319

[18] Robertson, J., McGoverin, C., Vanholsbeeck, F., Swift, S. (2019) Optimization of the Protocol for the LIVE/DEAD R BacLightTM Bacterial Viability Kit for Rapid Determination of Bacterial Load. Frontiers in Microbiology, 10, 1-13. 
https://doi.org/10.3389/fmicb.2019.00801

[19] Berney, M., Hammes, F., Bosshard, F., Weilenmann, H.-U. and Egli, T. (2007) Assessment and Interpretation of Bacterial Viability by Using The LIVE/DEAD BacLight Kit in Combination with Flow Cytometry. Applied and Environmental Microbiology, 73, 3283-3290. https://doi.org/10.1128/AEM.02750-06

[20] Stiefel, P., Schmidt-Emrich, S., Maniura-Weber, K. and Ren, Q. (2015) Critical aspects of Using Bacterial Cell Viability Assays with the Fluorophores SYTO9 and Propidium Iodide. BMC Microbiol, 15, Article No. 36. https://doi.org/10.1186/s12866-015-0376-X

[21] Netuschil, L., Auschill, T.M., Sculean, A. and Arweiler, N.B. (2014) Confusion over Live/Dead Stainings for the Detection of Vital Microorganisms in Oral Biofilms-Which Stain Is Suitable? BMC Oral Health, 14, Article No. 2. https://doi.org/10.1186/1472-6831-14-2

[22] Sarker, A.S.D., Naharb, L. and Kumarasamy, Y. (2007) Microtitre Plate-Based Antibacterial Assay Incorporating Resazurin as an Indicator of Cell Growth, and Its Application in the in Vitro Antibacterial Screening of Phytochemicals. Methods, 42, 321-324. https://doi.org/10.1016/j.ymeth.2007.01.006

[23] Lobato, R.C., Klafke, G.B. and Xavier, M.O. (2016) Reproducibility of Different Techniques Associated with Filtration in the Standardization of Aspergillus fumigatus Conidia Inoculum. Vittalle-Revista de Ciências da Saúde, 28, 84-89.

[24] Marsh, P.D. and Martin, M.V. (2005) Oral Microbiology. 4th Edition, Livraria e Editora Santos, São Paulo, 192 p.

[25] Reis, J. and Melo, P. (2003) Dental Caries, an Infectious Disease. Revista Portuguesa de Saúde Pública, 21, 84.

[26] Canettieri, A.C.V., Kretchetoff, F.Y., Fujarra, F.C., Moreira, D. and Unterkircher, C.S. (2006) Effect of Mononucleal Antibodies 56G on the Growth of Streptococcus mutans in Broth and on Accumulation of Dental Plaque in Vitro. Ciência Odontológica Brasileira, 9, 67-75.

[27] Koo, H., Gomes, B.P.F.A., Rosalen, P.L., Ambrosano, G.M.B., Park, Y.K. and Cury, J.A. (2000) In Vitro Antimicrobial Activity of Propolis and Arnica Montana against Oral Pathogens. Archives of Oral Biology, 45, 141-148. https://doi.org/10.1016/S0003-9969(99)00117-X

[28] Pereira, J.V., Pereira, M.S.V., Sampaio, F.C., Sampaio, M.C.C., Alves, P.M., Araújo, C.R.F., et al. (2006) In vitro Antibacterial and Antiadherence Effect of the Extract of the Punica granatum Linn. upon Dental Biofilm Microrganisms. Revista Brasileira de Farmacognosia, 16, 88-93. https://doi.org/10.1590/S0102-695X2006000100016

[29] Conde, N.C.O., Pereira, M.S.V., Bandeira. M.F.C.L., Venâncio, G.N., Oliveira, G.P. and Sampaio, F.C. (2015) In Vitro Antimicrobial Activity of Plants of the Amazon on Oral Biofilm Micro-Organisms. Revista Odonto Ciencia, 30, 179-183.

[30] Venâncio, G.N., Rodrigues, I.C., Souza, T.P., Marreiro, R.O., Bandeira, M.F.C.L. and Conde, N.C.O. (2015) Herbal Mouthwash Based on Libidibia ferrea: Microbiological Control, Sensory Characteristics, Sedimentation, $\mathrm{pH}$ and Density. Revista de Odontologia da UNESP, 44, 118-124.

https://doi.org/10.1590/1807-2577.1064 